\title{
НАУЧНОЕ ОБОСНОВАНИЕ КОГНИТИВНО-ИНФОРМАЦИОННОГО ПРОТЕЗИРОВАНИЯ (МЕДИКО-СОЦИОЛОГИЧЕСКИЙ АНАЛИЗ ЕСТЕСТВЕННОЙ РЕПАРАЦИИ САМОСОХРАНИТЕЛЬНЫХ МОТИВАЦИОННЫХ МАТРИЦ)
}

\author{
Худоногов И.Ю., Иванов А.С., Зарубинская Л.Г., \\ Певнева М.В., Чумаян А.Д.
}

Цель. Разработка информационно-когнитивной методологии оценки и регулирования индивидуального, группового, регионального и популяционного здоровья населения.

Задачи: 1) сформировать представления о мотивачионной матрице современных россиян; 2) разработать индикаторную систему для фиксации объема и качества сочиально-значимой информачии; 3) определить уровень «накопленной заболеваемости» (Н3) в группах с различной мотивачионной матрицей.

Методы. Предлагаемая нами методология включает самооченку физического здоровья (по критерию (Н3)) 1657 взросльх жителей Южного и Северо-Кавказского федеральных округов (возраст: 16-80 лет) на фоне измерения информационно-когнитивных параметров их личностной мотивационной матриць (MM). В ходе количественной оиенки параметров ММ была обоснована её дискретность, особенности заполнения ячеек и их влияние на НЗ, показана иелесообразность использования параметров ММ в качестве самосохранительного потенциала (СП), медицинская эффективность которого по критерию НЗ превышала соответствующие показатели традиционных факторов риска в 2-20 раз.

Информачионная часть СП включала сочиологическую регистраичию наличия (отсутствия) афферентного потока (градиента афферентации (ГА)) от сочиально значимых объектов (СЗО), а когнитивная - распознавание и осмысление приобретения или потери указан- 
ных СЗО. Использованные методы измерения актуальных суммарных опредмеченных потребностей (находящихся в фазе «приобретение» или «потеря») позволили вычислить среднее, оптимальное и максимально возможное количество ячеек ММ, удерживаемое человеком одновременно, рассчитать самосохранительный потенциал индивида, группы, или населения в иелом посредством регистрации фактов поступления информации от приобретенных или не поступления от потерянных в последнее время СЗО.

Результаты. В среднем по выборке позитивный градиент аф-

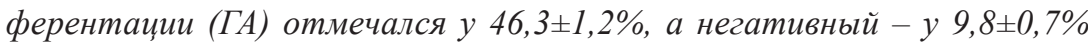

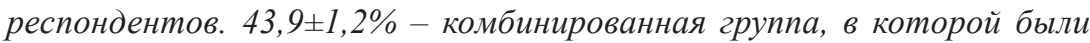
сконцентрированы участники опроса, у которых потери уравновешивались приобретениями и те, кто имели истинно нулевое значение ГА от социально значимого объекта - таких респондентов было около половины группы $(21,1 \pm 1,0 \%$ от выборки). С информационно-когнитивной точки зрения отсутствие приобретений и потерь соответствует нейрофизиологической норме популяиии, которая обеспечивает нако-

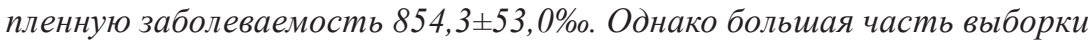
$(78,9 \pm 1,0 \%)$ активно изменяет суммарный ГА. При этом в соответствии с линейным трендом $\left(R^{2}=73,2 \%\right)$ потеря (приобретение) каждого СЗО изменяет Н3 на 10,9\% (что соответствует 274,7\%о) в сторону увеличения (уменьшения).

Выводы. При равных прочих условиях здоровье - это реагирование на потоковые характеристики информации (на ее объем и качество). Экономическая, политическая и сочиальная нестабильность действуют на популяциию опосредованно - через информационно-когнитивные параметры ММ.

Разработанные методы дают возможность оценить и спрогнозировать изменения индивидуального и общественного здоровья с использованием визуализации информаџионно-когнитивных потоков от имеющихся или утраченных СЗО.

Программы активной коррекиии уровня заболеваемости целесообразно разрабатывать на основе формирования новых медицинских (парамедицинских) СЗО - так называемых «когнитивно-информационных протезов» (КИП), способных восполнить ММ.

Ключевые слова: общественное здоровье; когнитивно-информационное протезирование; мотивационная матрица; социально значимый объект; градиент афферентации; моделизация; демоделизация. 


\title{
SCIENTIFIC SUBSTANTIATION \\ OF COGNITIVE-INFORMATIONAL PROSTHETICS \\ (MEDICAL-SOCIOLOGICAL ANALYSIS \\ OF NATURAL REPARATION OF SELF-PRESERVATION MOTIVATION MATRIX)
}

\author{
Khudonogov I.Yu., Ivanov A.S., Zarubinskaya L.G., \\ Pevneva M.V., Chumayan A.D.
}

Purpose. To develop an information-cognitive methodology for assessing and regulating individual, group and population health.

Tasks: 1) to form an idea of the motivational matrix of modern Russians; 2) to develop an indicator system for fixing the volume and quality of socially significant information; 3) to determine the level of "accumulated morbidity" (AM) in groups with different motivational matrix.

Materials and methods. Self-assessment of physical health by the criterion: AM (1,657 adults in the Southern and North Caucasus federal districts (age: 16-80 years)). Measurement of information-cognitive parameters of the personal motivational matrix (MM): discreteness, content of cells and their effect on AM. The expediency of using MM parameters as a self-preservation potential (SP) was shown. The medical efficacy of MM changes by AM criteria exceeded the corresponding indicators of traditional risk factors by 2-20 times. Information part of the joint venture included the sociological registration of the presence (absence) of the afferent flow (gradient of afferentation (GA)) from socially significant objects (SSO), and cognitive part-recognition and comprehension of the acquisition or loss of these SSO. The methods used to measure current aggregate identified needs (in the phase of "acquisition" or "loss") allowed to calculate the average, optimal and maximum possible number of MM cells held by a person simultaneously. The authors calculated the self-preservation potential of the individual, group and the population as a whole by registering the facts of the receipt of information from acquired or not received from the recently lost SSO.

Results. Positive gradient of afferentation (GA) was observed in $46.3 \pm$ $1.2 \%$, negative - in $9.8 \pm 0.7 \%$ of respondents on average in the sample. The remaining participants in the survey had a truly zero $G A$ value from a socially significant object. Absence of acquisitions and losses corresponds to the neurophysiological norm of the population, which provides the accumulated 
morbidity of $854.3 \pm 53.0 \%$. In accordance with the linear trend $\left(R^{2}=73.2 \%\right)$, the loss (acquisition) of each SSO changes the AM by 10.9\% (corresponding to $274.7 \%$ ) in the direction of increase (decrease).

Conclusions. Health is a response to the flow characteristics of information (its volume and quality) under equals other conditions. Economic, political and social instability affect the population indirectly through the information-cognitive parameters of MM. The developed methods make it possible to evaluate and predict changes in individual and public health using visualization of information-cognitive flows from existing or lost SSO. Programs of active correction of the incidence rate should be developed on the basis of the formation of new medical (paramedical) SSO - the so-called "cognitive-informational prostheses".

Keywords: public health; cognitive-informational prosthetics; motivational matrix; socially significant object; gradient of afferentation; modelization; demodelization.

\section{Введение}

Культура и особенно та ее часть, которая формирует нравственность современного общества и его мировоззрение, необоснованно принижена, не говоря уже о том, чтобы являться приоритетным направлением осмысленного развития [1, с. 20]. Вместе с тем, историческая ретроспектива показывает, каких высот может достичь социум и личность, наполненные соответствующим ментальным содержанием. Наилучшим подтверждением истинности указанного пути является практика. Так, теоретические суждения Аристотеля, спроецированные на Александра Македонского (некогда третьестепенного заштатного представителя провинциальной элитной группы) и с триумфом реализовались в глобальной геополитике. Построение в кротчайшие сроки величайшей мировой империи, простирающейся от Индийского до Атлантического океана, говорит, с одной стороны, о том, что все объективные предпосылки к этому уже были сформированы, и Аристотель это увидел, а с другой, что Александр был хорошим учеником (послушным инструментом в руках) Аристотеля, подтвердившим истинность теоретических построений своего учителя, выдающегося античного автора и естествоиспытателя.

Ключевым элементом представлений великого греческого философа являлось всеобъемлющее понятие «движение», с помощью которого он определял всё, включая такие частные понятия, как жизнь и здоровье. Обладая способностью к глубокому абстрактному мышлению, Аристо- 
тель-учитель, обращаясь к ученикам, тем не менее, пользовался вполне понятными и конкретными образами. Так, «жизнь» как «движение» он обозначал широко известным сегодня, но понимаемым слишком узко,

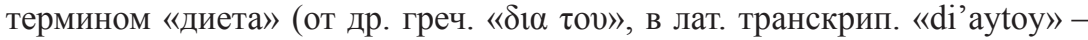
что дословно обозначало «через него»), т.е. два слова символизировали наличие потока чего-то (вещества, энергии и/или информации) через что-то [2, с. 394]. По мнению Аристотеля, жизнь характеризуется наличием хотя бы одного из следующих признаков движения: ум (движение мысли), ощущение (движение чувства), физическое движение или удержание покоя в пространстве, а также движение в смысле питания (выделения), упадка и роста (изменение структуры и размерности) [2, c. 396]. Пусковым механизмом указанного движения согласно Аристотелю является энтелехия. В энциклопедическом словаре [3] энтелехия (др. греч. $\dot{\varepsilon} v \varepsilon \lambda \varepsilon_{\varepsilon} \chi \varepsilon 1 \alpha$, в лат. транскрип. entelecheia) - это завершение, осуществленность, понятие философии Аристотеля, обозначающее осуществление какой-либо возможности бытия, а также движущий фактор этого осуществления (напр., душа как энтелехия тела), и выражающее единство четырех основных принципов бытия: аморфной материи, четко структурированной формы, действующей причины и цели. Учитывая цикличность времени $[4$, с. 7-10] можно утверждать, что существует как прямой (указанный Аристотелем) порядок следования событий (реализаций принципов), подразумевающий здоровье и жизнь, так и обратный порядок, описывающий болезнь и смерть, т.е. стремящийся к перемещению рассматриваемой системы в энтропию, где тро́ло (от др. греч.) - «тро-

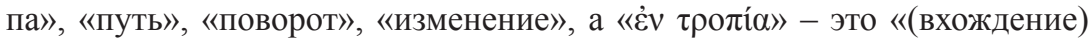
в поворот», «поворачивание», «превращение» - широко используемый в естественных науках термин, обозначающий вектор изменения состояния системы, направленный на разупорядочивание порядка. В то

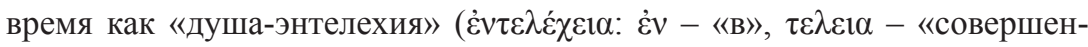
ство») - это сила естественного тела, обладающего возможностью жить [2, с. 395]. Отсюда очевидно произошел и термин «интеллект», который латиняне практически без искажений переняли из древнегреческого языка, и обозначает он дословно «(движение) в совершенство», т.е. туда, где все завершено (совершено, совершенно), а значит очень «далеко» от земного бытия и «близко» к Небу, к Богу, в отличие от современного толкования интеллекта, акцентирующегося на способности приспосабливаться к новым ситуациям. В связке четырех принципов бытия (материи, формы, действующей причины и цели) активную позицию занимает лишь одна 
сила - это действующая причина. Применительно к человеку латиняне назвали эту силу словом «мотив» (лат. movere - приводить в движение, толкать) - побуждение к действию. Отсюда мотор - это толкатель, двигатель, а мотив - это осмысленный ответ на вопрос: «Почему я это делаю (что меня заставляет это делать)»?

Следующий по важности принцип бытия - это «форма», что в современном прочтении может соответствовать принципу единства структуры и функции. Наиболее ярким примером такого единства является осанка как положение тела в пространстве, выражающееся положением разных сегментов тела по отношению друг к другу. Осанка управляется механизмами неврологического контроля [5, с. 180-181; 6, с. 67-70; 7, с. 10-15]. Живая мышечная ткань, занимающая в пространстве некоторое место, постоянно находится в состоянии определенного тонуса (греч. тон, тональность, напряжение) - состояния длительного стойкого возбуждения нервных центров, которое характеризуется частотой импульсов от 1 Гц (для гладкой мускулатуры) [8, с. 281-284] - до 238 Гц [9, с. 280-281] и более (для поперечнополосатых мышц), и на первый взгляд никак не связана с силой сокращения этих мышц. Следовательно, видимые нами признаки нарушения осанки есть реализация невидимого процесса дистонии соответствующих нейронов. Откуда же появляется эта дистония? Из множества причин выберем наиболее часто встречающуюся и поэтому наиболее хорошо изученную. Асимметричный кариес и последующее удаление пораженных зубов (или их травматическая потеря) приводят к нарушению функции пережевывания пищи. Нарушение состоит в том, что нагрузку принимают на себя интактные зубы, часть челюсти, на которой они расположены, и группа мышц, прикрепленных к этой части челюсти. Не являясь полноценным мышечные сокращением, тонус, тем не менее, обеспечивает новую форму организма, которая соответствует новой (измененной) функции. Подобные морфофункциональные модели и клинические случаи хорошо известны [10, с. 180-182; 11, с. 15-18; 12, c. 66-70], также хорошо известен и способ лечения - это восстановление целостности (симметричности) зубного ряда при помощи зубных протезов. Термин «протез» французского происхождения (франц. prothèse, от

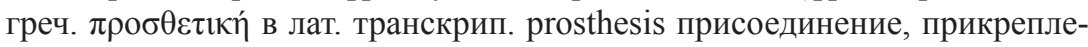
ние) - обозначает аппарат или приспособление, служащее для восполнения утраченной функции или замещения отсутствующей части тела или органа. В соответствии с рабочей гипотезой мотивационная матрица человека $[13$, с. 93-96] (MМ) является полным аналогом зубного ряда. Для 
нормального функционирования (насыщенной жизни и крепкого здоровья) каждому индивиду необходим полный набор мотивов, обеспечивающих достижение не только определенного жизненного биологического тонуса (напряжения - внутренней энергии), но и реализацию последнего принципа (этапа) тетрады превращений Аристотеля - достижение социально-психологического смысла. Выпадение одного или нескольких мотивов из ММ приводят к деформациям когнитивно-информационного пространства (КИП) человека, снижению тонуса, потере смысла и возникновению заболеваний. Формирование новых мотивов напротив гармонизирует КИП и обеспечивает быстрое выздоровление и увеличение продолжительности жизни.

Все вышесказанное определило цель нашего исследования.

\section{Цель работы}

Разработка информационно-когнитивной методологии оценки и регулирования индивидуального, группового, регионального и популяционного здоровья населения.

\section{Материалы и методы исследования}

Первичный материал был получен в результате социологического опроса 1657 взрослых жителей Южного и Северо-Кавказского федеральных округов (876 мужчин и 781 женщина в возрасте от 16 до 80 лет). Анкетирование проводилось в 2014-2016 гг. Рандомизированной выборке респондентов предлагалось осуществить самооценку физического здоровья (по критерию: «накопленная заболеваемость» (Н3)) на фоне измерения информационно-когнитивных параметров их личностной мотивационной матрицы (ММ). В ходе количественной оценки параметров ММ была исследована её дискретность, особенности заполнения ячеек и их влияние на Н3, показана целесообразность использования параметров ММ в качестве самосохранительного потенциала (СП). Методология включала оценку медицинской эффективности СП по критерию НЗ. Расчет медицинской эффективности (МЭ) как степени достижения медицинского результата при изменениях ММ выполнялся с использованием уравнений линейного и полиномиального трендов. Достоверность аппроксимации фактических данных характеризовалась соответствующим коэффициентом $\mathrm{R}^{2}$, рассчитанным по методу наименьших квадратов. Информационная часть СП включала социологическую регистрацию наличия (отсутствия) афферентного потока (градиента афферентации (ГА)) от 
социально значимых объектов (С3О), а когнитивная - распознавание и осмысление приобретения или потери указанных СЗО. Использованные методы измерения актуальных суммарных опредмеченных потребностей (находящихся в фазе «приобретение» или «потеря») позволили вычислить среднее, оптимальное и максимально возможное количество ячеек MM, удерживаемое человеком одновременно, рассчитать самосохранительный потенциал индивида, группы, или населения в целом посредством регистрации фактов поступления информации от приобретенных или не поступления от потерянных в последнее время СЗО. Статистическая значимость разницы показателей в группах сравнения рассчитывалась при помощи критерия Стьюдента. Ошибка репрезентативности для средних величин определялась по формуле:

$\mathrm{m}_{\mathrm{M}}= \pm \frac{\sigma}{\sqrt{\mathrm{n}}}$. Ошибка представительности относительных величин рассчитывалась по формуле: $\mathrm{m}_{\mathrm{p}}= \pm \frac{\sqrt{\mathrm{P} * \mathrm{q}}}{\mathrm{n}}$. Сила связи между признаками устанавливалась при помощи порядкового коэффициента корреляции (коэффициента ранговой корреляции (КРК) Спирмена).

\section{Результаты исследования и их обсуждение}

В среднем по выборке позитивный градиент афферентации (ГА) [14, c. 120-130] отмечался у $46,3 \pm 1,2 \%$, а негативный - у $9,8 \pm 0,7 \%$ респондентов. 43,9 $1,2 \%$ - комбинированная группа, в которой были сконцентрированы участники опроса, у которых потери уравновешивались приобретениями и те, кто имели истинно нулевое значение ГА от социально значимого объекта - таких респондентов было около половины группы $(21,1 \pm 1,0 \%$ от выборки). С информационно-когнитивной точки зрения отсутствие приобретений и потерь соответствует нейрофизиологической норме популяции, которая обеспечивает накопленную заболеваемость $854,3 \pm 53,0 \%$. Однако большая часть выборки $(78,9 \pm 1,0 \%)$ активно изменяет суммарный ГА. При этом в соответствии с линейным трендом $\left(\mathrm{R}^{2}=\right.$ $73,2 \%$ ) потеря (приобретение) каждого С $3 О$ изменяет НЗ на 10,9\% (что соответствует $274,7 \%$ ) в сторону увеличения (уменьшения) (рис. 1).

Для обеспечения соизмеримости признаков применялись показатели наглядности, выраженные в \%. За 100\% численности был принят размер самой представительной группы с ГА=0 (727 респондентов). За 100\% заболеваемости был взят наивысший уровень (3300\%), выявленный в группе с минимальным ГА (-3). Средневыборочный уровень накопленной заболеваемости (Н3) составил 1042,2士27,4\%. Он и 
был использован в дальнейшем для расчета прогнозных значений показателей, а также медицинской эффективности моделизации (процесса построения нейронального ансамбля, отражающего рецепируемые признаки присвоенного СЗО) и демоделизации (процесса разрушения нейронального ансамбля утраченного СЗО), выраженной через ГА. За 100\% возможного суммарного ГА было принято его прогностическое значение $+9,5$ единиц. Произвольно выбранный угол наклона линии тренда ГА $(10,526)$ обеспечил максимальную наглядность и симметричность по отношению к трендам заболеваемости. Тип распределения числа респондентов в группах с различным ГА в исследованной выборке стремился к нормальному.

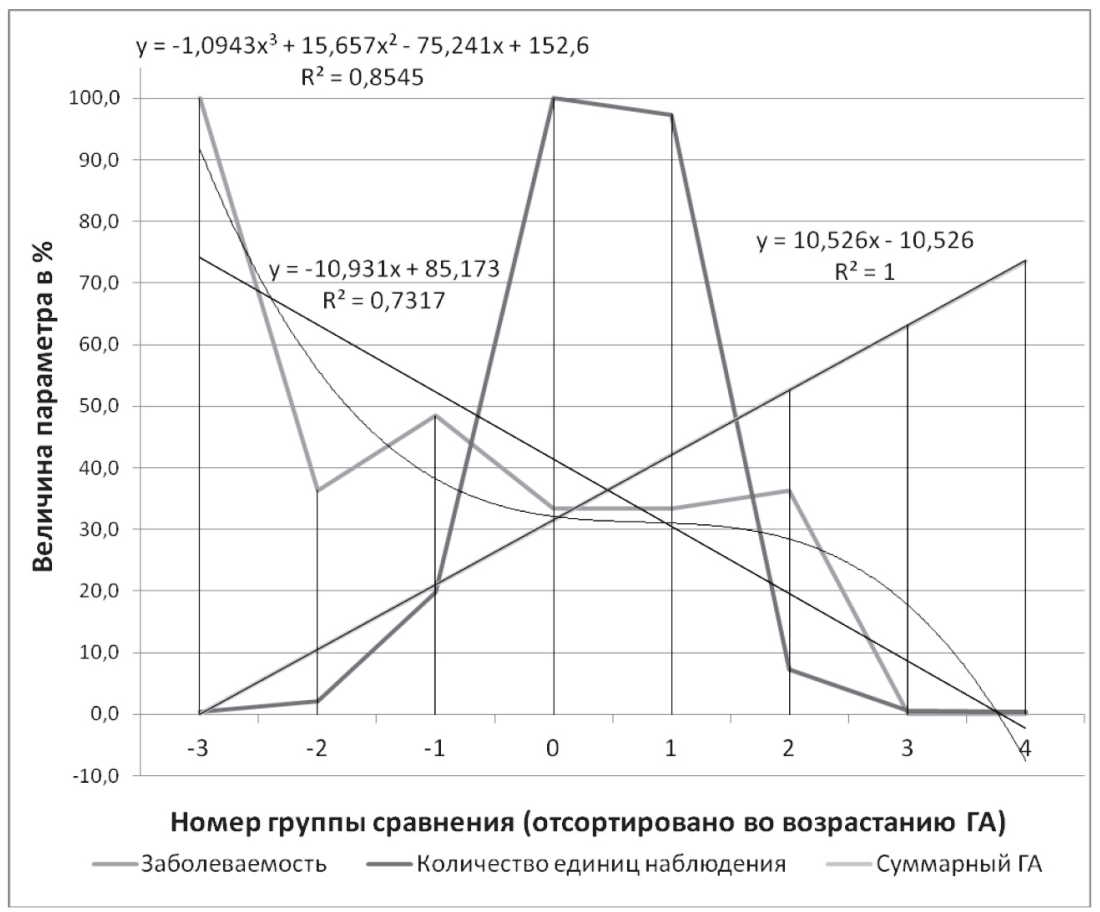

Рис. 1. Медицинская эффективность естественной репарации самосохранительных мотивационных матриц

В соответствии с линейным трендом (ЛТ) график аппроксимации имеет формулу: 


$$
\begin{gathered}
y=-10,931 x+85,173 \\
R^{2}=0,7317
\end{gathered}
$$

Формула 1 позволяет интерполировать уровень накопленной заболеваемости (табл. 1).

Таблица 1.

Прогнозные значения накопленной заболеваемости (Н3)

\begin{tabular}{|c|c|c|c|c|}
\hline $\begin{array}{c}\text { № } \\
\text { группы }\end{array}$ & & $\begin{array}{c}\text { Суммарный ГА } \\
\text { (в единицах) }\end{array}$ & $\begin{array}{c}\text { Н3 } \\
\text { (в \% к фактич. уров- } \\
\text { ню 1-й группы) }\end{array}$ & $\begin{array}{c}\text { Н3 } \\
\text { (в \%о прогноз от } \\
\text { уровня 4-й группы) }\end{array}$ \\
\hline $0^{*}$ & \multirow{9}{*}{ 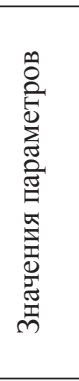 } & -4 & 85,2 & 2140,9 \\
\hline 1 & & -3 & 74,3 & 1866,2 \\
\hline 2 & & -2 & 63,3 & 1591,5 \\
\hline 3 & & -1 & 52,4 & 1316,9 \\
\hline 4 & & 0 & 41,5 & $1042,2 * *$ \\
\hline 5 & & 1 & 30,5 & 767,5 \\
\hline 6 & & 2 & 19,6 & 492,9 \\
\hline 7 & & 3 & 8,7 & 218,2 \\
\hline 8 & & 4 & $-2,2$ & $-56,5$ \\
\hline $\begin{array}{r}\text { Гради } \\
\text { равном } \\
\text { прираг }\end{array}$ & $\begin{array}{l}\text { Іты } \\
\text { ного } \\
\text { ния }\end{array}$ & 1 & 10,9 & 274,7 \\
\hline
\end{tabular}

с учетом линейного приращения

Примечание: * - группа в выборке не определена, значения интерполированы; ** - «нормальный» уровень заболеваемости, соответствующий нулевому уровню суммарного ГА.

Полиномиальный ЛТ отразил фактическую заболеваемость в следующем уравнении (2):

$$
\begin{gathered}
y=-1,0943 x^{3}+15,657 x^{2}-75,241 x+152,6 \\
R^{2}=0,8545
\end{gathered}
$$

Достоверность аппроксимации уравнения 2 выше 85\%, следовательно, и точность прогноза на исследуемом отрезке колебаний ГА также выше, чем при линейном прогнозировании (табл. 2).

При анализе связи между изменениями суммарного ГА и собственно Н3, а также ее сглаженными вариантами (линейным и полиномиальным трендами) было показано (табл. 3), что во всех случаях связь обратная и сильная. 
Таблица 2.

Прогнозные значения накопленной заболеваемости (Н3) с учетом полиномиального приращения

\begin{tabular}{|c|c|c|c|c|}
\hline $\begin{array}{c}\text { № } \\
\text { группы }\end{array}$ & & $\begin{array}{c}\text { Суммарный ГА } \\
\text { (в единицах) }\end{array}$ & $\begin{array}{c}\text { Н3 } \\
\text { (в \% к фактич. уров- } \\
\text { ню 1-й группы) }\end{array}$ & $\begin{array}{c}\text { Н3 } \\
\text { (в \%о прогноз от } \\
\text { уровня 4-й группы) }\end{array}$ \\
\hline $0^{*}$ & \multirow{9}{*}{ 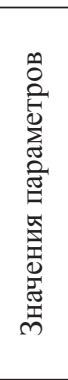 } & -4 & 152,6 & 4952,5 \\
\hline 1 & & -3 & 91,9 & 2983,3 \\
\hline 2 & & -2 & 56,0 & 1817,2 \\
\hline 3 & & -1 & 38,2 & 1241,2 \\
\hline 4 & & 0 & 32,1 & $1042,2 * *$ \\
\hline 5 & & 1 & 31,0 & 1007,1 \\
\hline 6 & & 2 & 28,4 & 922,9 \\
\hline 7 & & 3 & 17,8 & 576,4 \\
\hline 8 & & 4 & $-7,6$ & $-245,4$ \\
\hline & ади & гы приращени & заболеваемости не p & вномерные \\
\hline
\end{tabular}

Примечание: * группа в выборке не определена, значения интерполированы; ** - «нормальный» уровень заболеваемости, соответствующий нулевому уровню суммарного ГА.

Таблица 3.

Прогностическая значимость различных отображений накопленной заболеваемости (Н3) с учетом корреляционных параметров

\begin{tabular}{|l|c|c|c|}
\hline \multicolumn{1}{|c|}{ Сопоставляемые переменные } & $r$ & $\begin{array}{c}\text { Статистиче- } \\
\text { ская погреш- } \\
\text { ность КРК } \\
\left( \pm s_{r}\right)\end{array}$ & $\begin{array}{c}\left(s_{r} / r\right) * 100 \\
(\text { в \%) }\end{array}$ \\
\hline Линейный тренд Н3 & $-1,00$ & 0,00 & 0,0 \\
\hline Полиномиальный тренд Н3 & $-0,89$ & 0,18 & 20,7 \\
\hline $\begin{array}{l}\text { Фактическая Н3 в экспериментальных } \\
\text { группах }\end{array}$ & $-0,86$ & 0,21 & 24,4 \\
\hline
\end{tabular}

В ходе социологического опроса экспериментальной группы взрослого населения было установлено, что средневыборочный суммарный ГА составляет +0 . Следовательно, ориентировочный уровень здоровья экспериментальной группы по индикатору накопленной заболеваемости (H3) будет соответствовать среднему уровню по популяции, и составит 1042\%. Если ГА составил -3, то мы вправе ожидать, что НЗ в экспери- 
ментальной группе повысится как по линейному, так и по полиномиальному тренду и будет равняться от 1866 до 2983\%о. Приведенные примеры иллюстрируют использование ГА в качестве диагностического и прогностического инструмента, точность которого при линейном отображении тренда составляет 73\% соответствия исходным значениям, и $85 \%$ соответствия при построении полиномиального тренда (рис. 1).

Кроме практических аспектов оценки, прогноза и регулирования О3 методика расчета ГА имеет важное теоретическое значение. Так, было выяснено, что в целом по выборке наиболее оптимальным вне зависимости от полярности ГА является функционирование 1 НА, обслуживающего 1 СЗО. Таких респондентов было около половины выборки, более четверти респондентов имеют 2 активно функционирующих НА (табл. 4), одна пятая участников опроса находится в стабильном состоянии $(\Gamma A=0)$.

Таблица 4.

Распределение респондентов по количеству НА, функционирующих одновременно

\begin{tabular}{|c|c|c|}
\hline Количество НА & Абс. численность группы & Численность группы (в \%) \\
\hline 0 & 350 & 21,1 \\
\hline 1 & 815 & 49,2 \\
\hline 2 & 438 & 26,4 \\
\hline 3 & 43 & 2,6 \\
\hline 4 & 10 & 0,6 \\
\hline 5 & 1 & 0,1 \\
\hline Всего & 1657 & 100,0 \\
\hline
\end{tabular}

Это нейрофизиологическая норма популяции, которой соответствует H3 $=854,3 \pm 53,0 \%$. Указанный уровень Н3 статистически значимо ( $<<0,01$; $\mathrm{t}=3,1)$ ниже, чем уровень средневыборочной Н3, равной $1042,2 \pm 27,4 \%$. Это свидетельствует о том, что эксперименты с приватизацией и деприватизацией (депривацией) небезопасны с точки зрения вреда здоровью в любом возрасте [15, с. 13-15]. При этом среднегрупповое минимально возможное суммарное количество НА, находящихся в стадии моделизации или демоделизации, не может быть меньше одного. Максимально возможное количество НА, находящихся в стадии моделизации или демоделизации, не превышает четыре (в качестве казуистики можно привести 1 респондента, который задекларировал 5 C3О (4 потери и 1 приобретение) при нормальном уровне Н3) (рис. 2). 


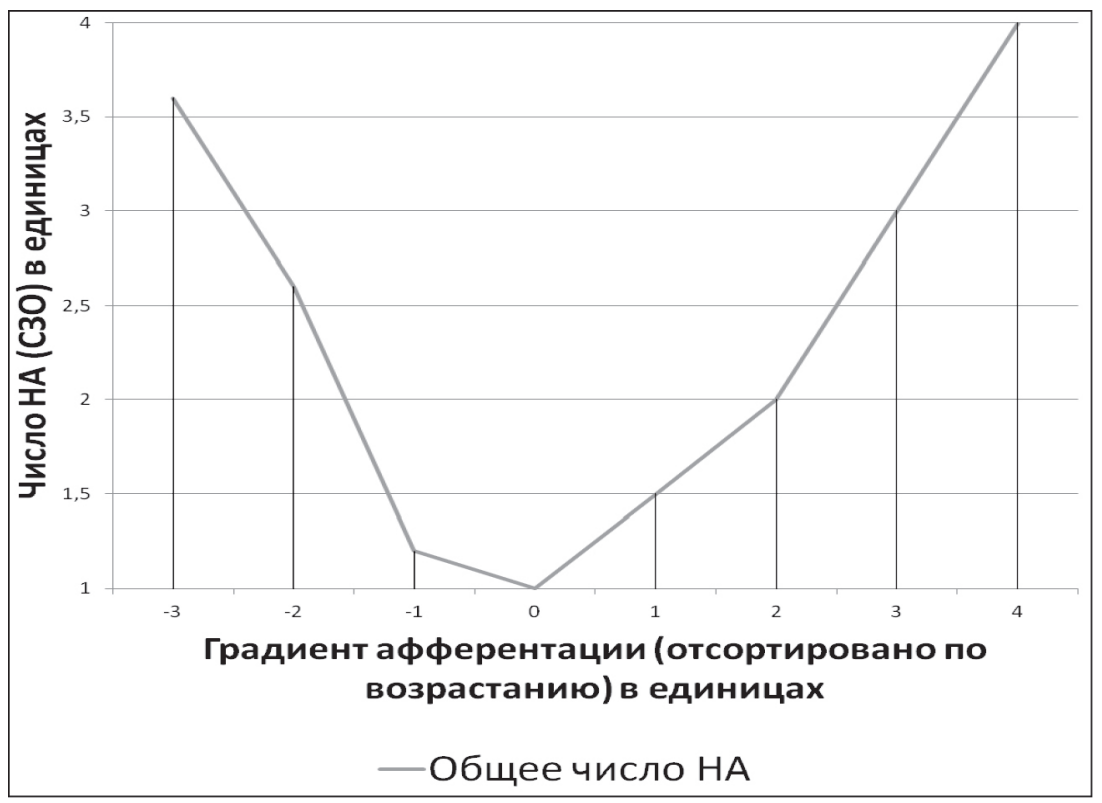

Рис. 2. Среднегрупповое число НА (С3О) у респондентов с различным уровнем суммарного ГА

Тем не менее, в масштабах всей выборки изменения вектора ГА приводят при моделизации к резкому улучшению здоровья, при демоделизации к трехкратному повышению НЗ. Иными словами, риски обвального ухудшения здоровья растут по мере увеличения количества присвоенных СЗО. Если развернуть рассматриваемое явление во времени, но вместо абстрактно текущих часов, недель, месяцев или лет взять конкретные события (появление нового заболевания), то выявляется интересная закономерность: каждый качественный переход (от точки «0 заболеваний» к точке «1 заболевание», от точки «1 заболевание» к точке «2 заболевания» и т.д.) начинается с потери одного (двух, трех) С3О, а заканчивается приобретением одного (двух, четырех) СЗО. Иными словами, пока человек расширяет круг привязанностей (СЗО) - он имеет стабильное здоровье, как только круг (воронка) привязанностей схлопывается - здоровье резко переходит на более низкий уровень (рис. 3).

Значительный интерес представляет возрастная динамика формирования СЗО (НА) на групповом уровне (рис. 4). 


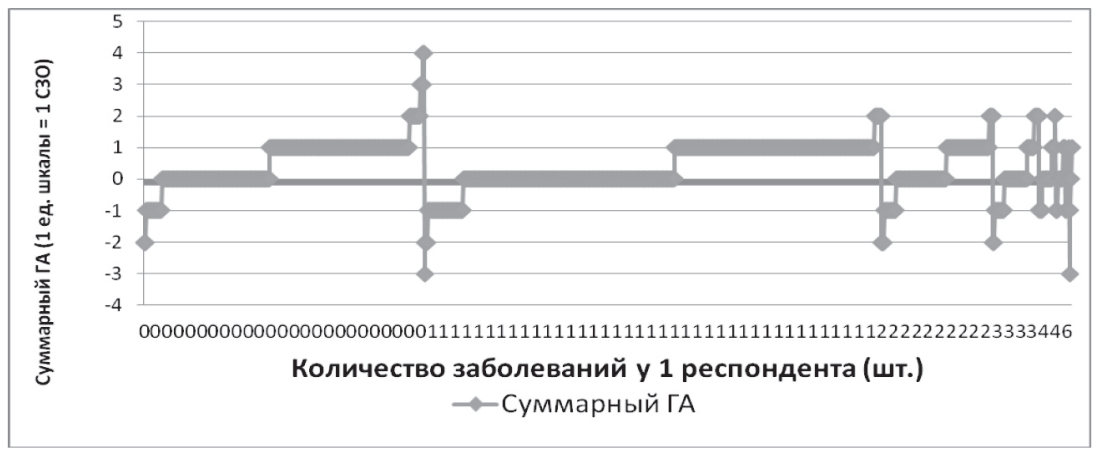

Pис. 3. Динамика суммарного ГА в последовательности респондентов, ранжированных по количеству имеющихся заболеваний

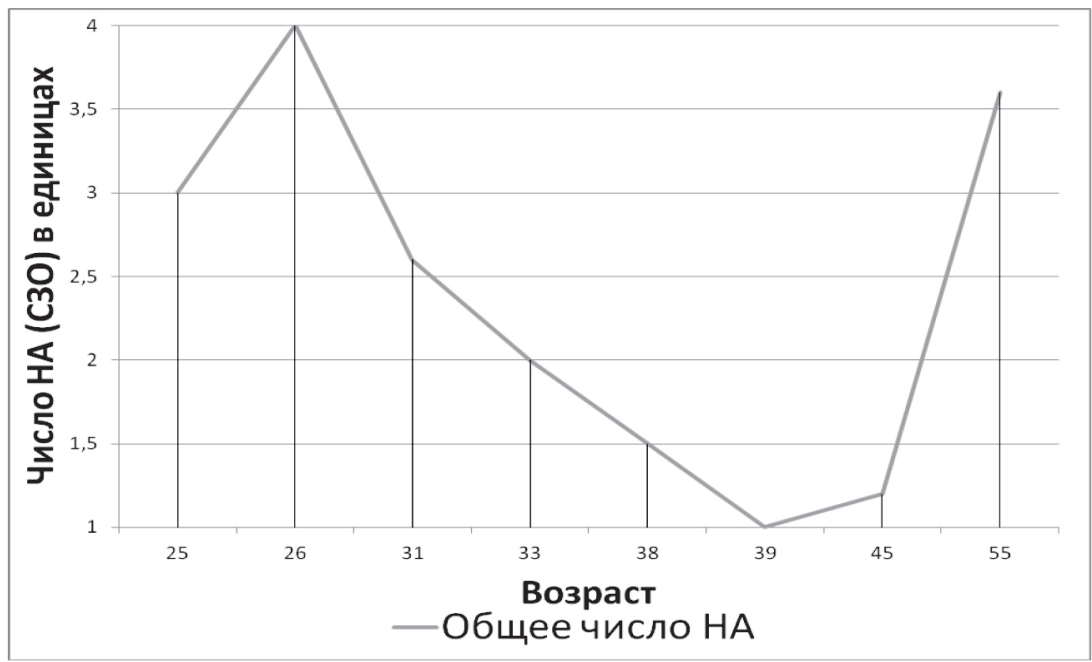

Рис. 4. Возрастные изменения среднегруппового числа НА (С3О) у респондентов с различным уровнем суммарного ГА.

Несмотря на то, что средний по выборке возраст составил $36,7 \pm 0,5$ лет, самая многочисленная группа респондентов с минимальным среднегрупповым числом НА, равным единице, оказалась старше (39 лет). Любое движение от точки 39 лет: в сторону увеличения до 55, или в сторону уменьшения до 26 лет сопровождалось ростом числа СЗО (НА). В 26 лет их в среднем по группе 4 СЗО, в 55 лет - 3,6 С3О. Разница в пиках 
принципиальная - в 26 лет выполняется максимально возможный набор СЗО (их присвоение), а в 55 - СЗО в основном отчуждаются. Более точная картина потерь и приобретений в возрастной развертке представлена на рисунке 5.

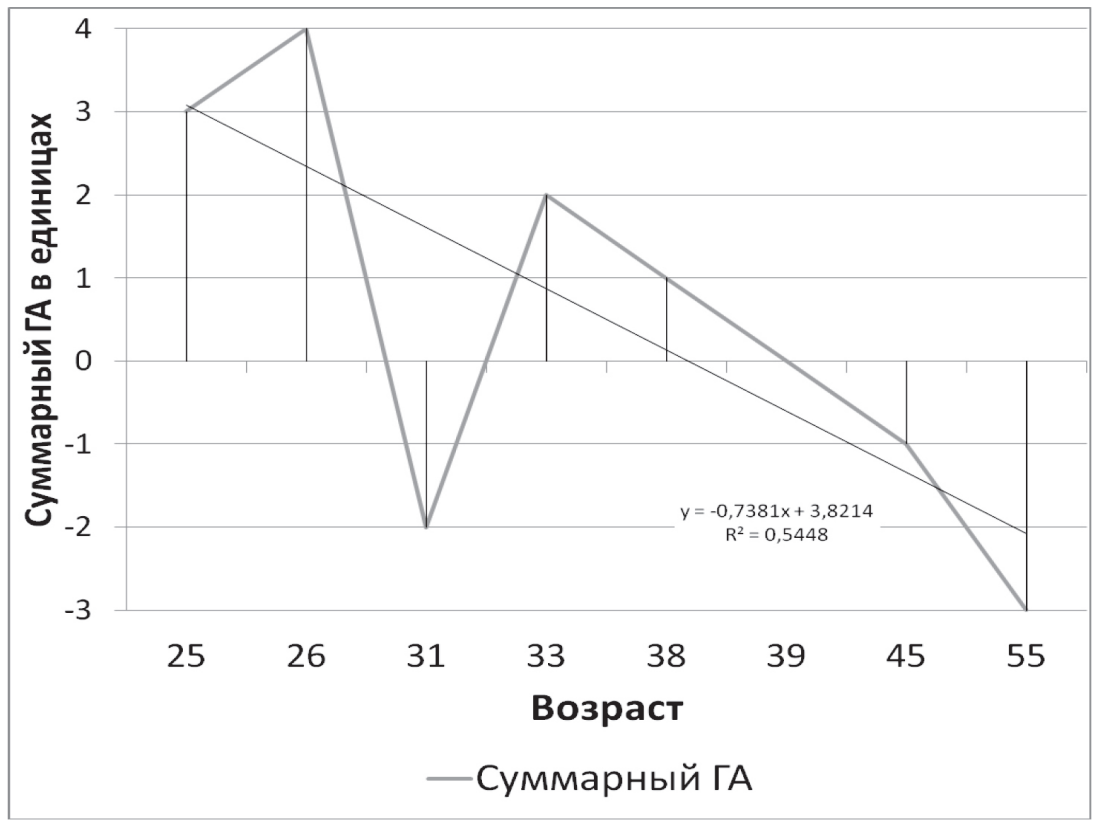

Рис. 5. Возрастная динамика уровня суммарного ГА

Общая тенденция отражена ЛТ достаточно отчетливо - за 30 лет (от 25 до 55 лет) в среднем по выборке респонденты теряют пять СЗО. Однако возрастная группа 31 год выбивается из общего правила и характеризуется резким снижением суммарного ГА до уровня «-2» СЗО. Не менее интересные тенденции обнаружились при анализе гендерной структуры групп (рис. 6).

Наиболее сбалансированной по полу оказалась группа ГА=0 (H3= $1042,2 \%$ ). Линейные тренды с вероятностью безошибочного прогноза $81 \%$ позволяют утверждать, что женщины в три раза чаще, чем мужчины теряют СЗО и соответственно обеспечивают $3 / 4$ прироста НЗ. Мужчины напротив, доминируют в той же пропорции в группе не болеющих приобретателей четырех СЗО одновременно. 


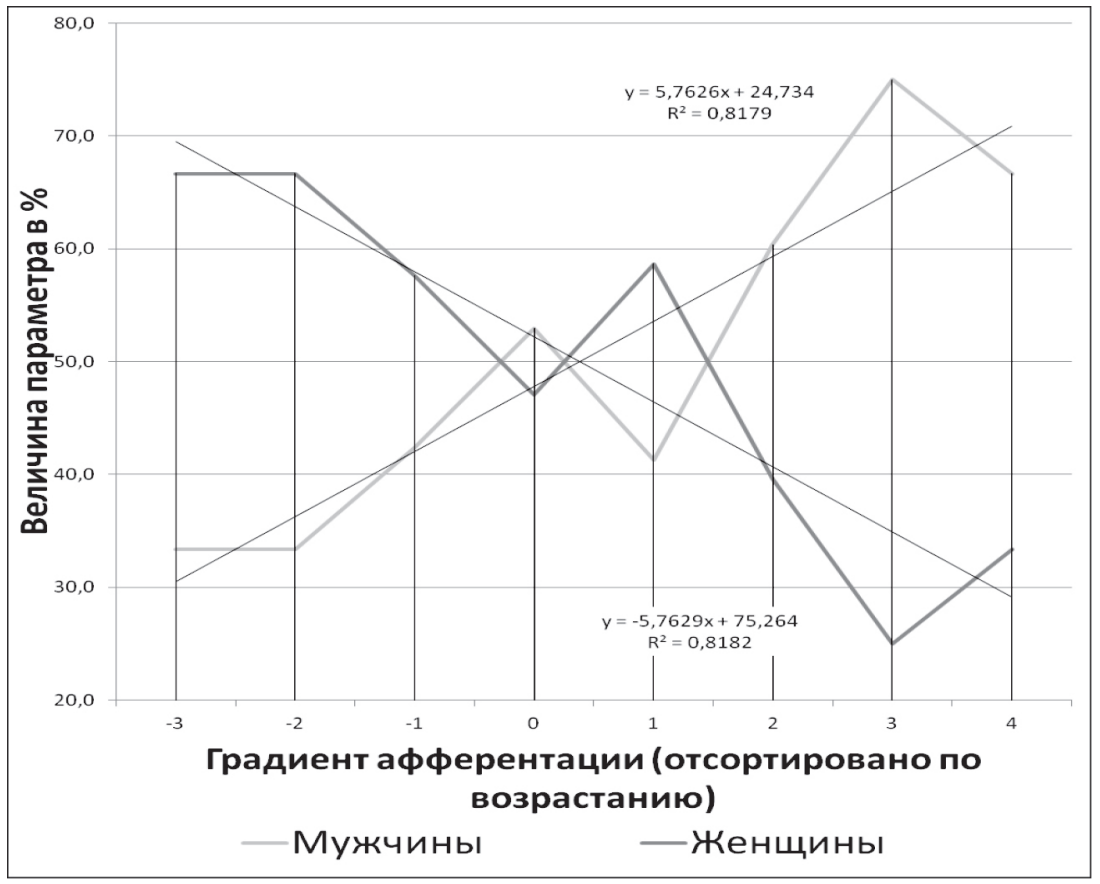

Рис. 6. Распределение по полу респондентов из групп с различным уровнем суммарного ГА

\section{Заключение}

Полученные результаты позволяют утверждать, что при равных прочих условиях здоровье - это реагирование на потоковые характеристики информации (на ее объем и качество). Экономическая, политическая и социальная нестабильность действуют на популяцию опосредованно через информационно-когнитивные параметры ММ. При этом рост количества СЗО, получаемых в собственность, увеличивает риски ухудшения здоровья при их утрате в период наступления кризисов.

Разработанные методы дают возможность оценить и спрогнозировать изменения индивидуального и общественного здоровья с использованием визуализации информационно-когнитивных потоков от имеющихся или утраченных СЗО.

Программы активной коррекции уровня заболеваемости целесообразно разрабатывать на основе формирования новых медицинских (па- 
рамедицинских) СЗО - так называемых «когнитивно-информационных протезов» (КИП), не зависящих от состояния экономики или политики (внешних условий), но всегда находящихся внутри нас и напрямую обеспечивающих целостность мотивационной матрицы, уровень здоровья и продолжительность жизни. Таким КИП может стать любой информационный контент, поступающий от любого авторитетного источника, отражающий любой предмет материального или духовного мира, который может быть присвоен и не может быть отчужден. Например, врач-кардиолог подробно рассказывает пациенту (или группе пациентов) о структуре и функционировании сердца, способах контроля его параметров. Он, таким образом, формирует ячейки самосохранительной мотивационной матрицы - сообщает пациенту необходимые для моделизации знания, а затем заполняет эти ячейки индивидуальной значимой медицинской информацией, полученной в результате объективного обследования. Указанная информация подтвердит уровень здоровья и правильность жизненной стратегии, или поможет оценить риски развития того, или иного заболевания. В результате коммуникации пациент в состоянии ощутить себя хозяином (владельцем и управленцем) собственного биосоциального организма (механизма), готовым активно сопротивляться всяческим попыткам отстранить его от контроля за всеми составляющими собственного здоровья. Иными словами, стратегическое партнерство врача и пациента на современном этапе развития здравоохранения должно начинаться с КИП и продолжаться медицинским сопровождением (диагностическим, аналитическим и методическим) и делегированием полномочий, т.е. самосохранением как активной профилактикой посредством мотивации.

\section{Список литературы}

1. Зарубинская Л.Г. Значение культуры в жизни общества и в формировании нравственного мировоззрения врача // Духовно-нравственное воспитание в Ростовском государственном медицинском университете Материалы XX Юбилейных Димитриевских образовательных чтений. Под общей редакцией С.В. Шлыка. 2015. С. 20-25.

2. Аристотель. Сочинения в четырех томах. Т.1. Ред. В.Ф. Асмус. М., «Мысль», 1976. 550 с.

3. Толковый словарь. URL: http://tolkslovar.ru/ie1728.html (дата обращения: 12.01.2018).

4. Гончаренко А.П. Деформация мирового экономического цикла // Экономические науки. 2016. № 139. С. 7-11. 
5. Gangloff P., Perrin PP. Unilateral trigeminal anaesthesia modifies postural control in human subjects. Neurosci Lett. 2002 Sep 20;330(2): 179-182.

6. Токаревич И.В., Сакадынец А.О. Зависимость специфичности аномалий зубных рядов от особенностей сколиотической деформации позвоночника // Современная стоматология. 2017. № 1 (66). С. 66-71.

7. Сакадынец А.О. Нарушение прикуса и особенности его коррекции при сколиозе: автореф. дис. ... канд. мед. наук по специальности 14.01.14 - стоматология / Сакадынец Александр Олегович; УО «Белорус. гос. мед. ун-Т». Минск, 2011. 20 с.

8. Лычкова А.Э., Костюченко Л.Н., Пузиков А.М. Электромиография при нарушениях моторной функции желудочно-кишечного тракта // European Scientific Conference сборник статей V Международной научно-практической конференции: в 3 частях. 2017. С. 281-284.

9. Зарипова Ю.Р., Мейгал А.Ю., Макарова В.И. Развитие периферического отдела двигательной системы ребенка первых трех лет жизни по данным накожной электромиографии // Педиатрическая фармакология. 2015. Т. 12. № 3. C. 277-282.

10. Gangloff P., Perrin PP. Unilateral trigeminal anaesthesia modifies postural control in human subjects. Neurosci Lett. 2002 Sep 20;330(2):179-182.

11. Сакадынец А.О. Нарушение прикуса и особенности его коррекции при сколиозе: автореф. дис. ... канд. мед. наук / УО «Белорус. гос. мед. ун-т». Минск, 2011. 20 с.

12. Токаревич И.В., Сакадынец А.О. Зависимость специфичности аномалий зубных рядов от особенностей сколиотической деформации позвоночника // Современная стоматология. 2017. № 1 (66). С. 66-71.

13. Худоногов И.Ю. Групповая мотивационная матрица как регулятор общественного здоровья (структурно-функциональный анализ) // Современные подходы к продвижению здоровья. Эл. ресурс (CD-Диск). 2016. С. 93-96.

14. Худоногов И.Ю., Иванов А.С., Кудинова Н.А., Пивненко Н.М. Количественная оценка информационно-когнитивной составляющей нестабильности показателей общественного здоровья в условиях рыночной экономики (значение для медицинских организаций) // Наука. Промышленность. Образование. Культура. Формирование духовно-нравственного и физического здоровья нации Материалы Х съезда Петровской академии наук и искусств. 2017. C. $120-130$.

15. Присяжная Н.В. Влияние внесемейной социализации на социальное поведение и специфику постинтернатной адаптации сирот // Социология медицины. 2012. № 1. С. 13-17. 


\section{References}

1. Zarubinskaja L.G. Duhovno-nravstvennoe vospitanie v Rostovskom gosudarstvennom medicinskom universitete Materialy XX Jubilejnyh Dimitrievskih obrazovatel'nyh chtenij [Spiritual and Moral Education in the Rostov State Medical University Materials of the XX Anniversary Dimitriev Education Readings]. Ed. S.V. Shlyka. 2015, pp. 20-25.

2. Aristotel'. Sochinenija $v$ chetyreh tomah [Aristotle. Works in four volumes]. V.1. ed. V.F. Asmus. M., «Mysl'», 1976. 550 p.

3. Tolkovyj slovar' [Explanatory dictionary]. http://tolkslovar.ru/ie1728.html

4. Goncharenko A.P. Jekonomicheskie nauki. 2016. № 139. S. 7-11.

5. Gangloff P., Perrin PP. Unilateral trigeminal anaesthesia modifies postural control in human subjects. Neurosci Lett. 2002 Sep 20;330(2):179-182.

6. Tokarevich I.V., Sakadynec A.O. Sovremennaja stomatologija. 2017. № 1 (66), pp. 66-71.

7. Sakadynec A.O. Narushenie prikusa i osobennosti ego korrekcii pri skolioze [Balsy violation and peculiarities of its correction in scoliosis]. Minsk, 2011. $20 \mathrm{p}$.

8. Lychkova A.E., Kostyuchenko L.N., Puzikov A.M. European Scientific Conference sbornik statej $V$ Mezhdunarodnoj nauchno-prakticheskoj konferencii [European Scientific Conference, a collection of articles of the V International Scientific and Practical Conference]. 2017, pp. 281-284.

9. Zaripova Yu.R., Meigal A.Yu., Makarova V.I. Development of an infant's peripheral motor system within the first 3 years of life as studied using surface electromyography. Pediatricheskaja farmakologija. 2015. V. 12. № 3, pp. 277-282.

10. Gangloff P, Perrin PP. Unilateral trigeminal anaesthesia modifies postural control in human subjects. Neurosci Lett. 2002 Sep 20;330(2):179-182.

11. Sakadynec A.O. Narushenie prikusa i osobennosti ego korrekcii pri skolioze [Violation of the bite and features of its correction in scoliosis]. Minsk, 2011. $20 \mathrm{p}$.

12. Tokarevich I., Sakadynets A. Sovremennaja stomatologija. 2017. № 1 (66), pp. 66-71.

13. Hudonogov I.Ju. Sovremennye podhody k prodvizheniju zdorov'ja [Modern approaches to promoting health Electronic resource]. 2016, pp. 93-96.

14. Khudonogov I.Yu., Kudinova N.A., Ivanov A.I., Pivnenko N.M. Quantitative assessment of informational-cognitive component of the public health indicators' instability in the conditions of market economy (value for out-patients' departments). Nauka. Promyshlennost'. Obrazovanie. Kul'tura. Formiro- 
vanie duhovno-nravstvennogo i fizicheskogo zdorov'ja nacii Materialy $X$ sezda Petrovskoj akademii nauk $i$ iskusstv [Science. Industry. Education. Culture. Formation of the spiritual, moral and physical health of the nation Materials of the 10th congress of the Petrovsky Academy of Sciences and Arts]. 2017, pp. 120-130.

15. Prisyajnaya N.V. The impact of out-family socialization on the social behavior and specificity of post-children home adaptation of orphans. Sociologija mediciny. 2012. № 1, pp. 13-17.

\section{ДАННЫЕ ОБ АВТОРАХ}

Худоногов Игорь Юрьевич, кандидат медицинских наук, старший преподаватель кафедры общественного здоровья и здравоохранения №1 с курсом истории медицины

Ростовский государственньй медииинский университет пер. Нахичеванский, 29, г. Ростов-на-Дону, Российская Федерация fux1@ya.ru

Иванов Александр Сергеевич, кандидат медицинских наук, заведующий кафедрой стоматологии ФПК и ППС

Ростовский государственный медицинский университет пер. Нахичеванский, 29, г. Ростов-на-Дону, Российская Федерация

Зарубинская Любовь Григорьевна, кандидат медицинских наук, доцент кафедры общественного здоровья и здравоохранения №1 с курсом истории медицины

Ростовский государственный медицинский университет пер. Нахичеванский, 29, г. Ростов-на-Дону, Российская Федерация

Певнева Марина Вадимовна, кандидат медицинских наук, доцент кафедры «Спортивные дисциплины» Донской государственный технический университет пл. Гагарина, 1, Ростов-на-Дону, 344002, Российская Федераиия

Чумаян Александр Дртадович, ассистент кафедры стоматологии ФПК и ППС

Ростовский государственный медицинский университет пер. Нахичеванский, 29, г. Ростов-на-Дону, Российская Федерация 


\section{DATA ABOUT THE AUTHORS}

Khudonogov Igor Yurievich, Candidate of Medical Sciences, Senior Lecturer, Chair of Public Health and Health No. 1 with a Course in the History of Medicine

Rostov State Medical University

29, Nakhichevansky Str., Rostov-on-Don, Russian Federation fux1@ya.ru

Ivanov Alexander Sergeevich, Candidate of Medical Sciences, Head of the Department of Dentistry Rostov State Medical University 29, Nakhichevansky Str., Rostov-on-Don, Russian Federation

Zarubinskaya Lyubov Grigoryevna, Candidate of Medical Science, Associate Professor of the Department of Public Health and Health No. 1 with a Course in the History of Medicine Rostov State Medical University 29, Nakhichevansky Str., Rostov-on-Don, Russian Federation

Pevneva Marina Vadimovna, Candidate of Medical Sciences, Associate Professor of the Department of Sports Disciplines Don State Technical University pl. Gagarina, 1, Rostov-on-Don, 344002, Russian Federation

Chumayan Alexander Dtradovich, Assistant of the Department of Stomatology Rostov State Medical University 29, Nakhichevansky Str., Rostov-on-Don, Russian Federation 